\title{
Recycling behavior of private households: an empirical investigation of individual preferences in a club good experiment
}

\author{
Roland Menges ${ }^{1}$. Janis Cloos $^{1} \cdot$ Matthias Greiff ${ }^{1} \cdot$ Jacob Wehrle $^{1} \cdot$ Daniel Goldmann $^{2} \cdot$ Lisa Rabe $^{2}$
}

Received: 7 January 2020 / Accepted: 23 August 2020 / Published online: 13 September 2020

(c) The Author(s) 2020

\begin{abstract}
While recycling helps to limit the use of primary resources, it also requires considerable technological investments in regional circular flow systems. The effectiveness of recycling systems, however, also depends on household behavior. Therefore, current research increasingly focuses on behavioral and psychological theories of altruism, moral behavior, and social preferences. From an economic perspective, recycling systems can be understood as public goods with contributions resulting in positive externalities. In this context, the literature shows that recycling behavior highly depends on the perception of how others behave. In neutrally framed public good experiments, contributions tend to increase when alternative public goods are offered and group identity is generated. We aim to contribute to this discussion by observing household behavior concerning recycling opportunities in controlled settings. For this purpose, we study a laboratory experiment in which individuals contribute to recycling systems: At first, only one public recycling system (public good) is offered. After dividing societies into two clubs, "high" and "low" according to their environmental attitudes, excludable club systems (club goods) are added as alternative recycling options for each club. The results of our pilot experiment show that adding a more exclusive recycling club option increases individual contributions to recycling compared with a pure public good framework. However, this increase in cooperation is only significant for those clubs where members with higher environmental attitudes are pooled.
\end{abstract}

Jacob Wehrle

jacob.wehrle@tu-clausthal.de

1 Institute of Management and Economics, Clausthal University of Technology, Clausthal-Zellerfeld, Germany

2 Institute of Mineral and Waste Processing, Waste Disposal and Geomechanics, Clausthal University of Technology,

Clausthal-Zellerfeld, Germany 


\section{Graphic abstract}

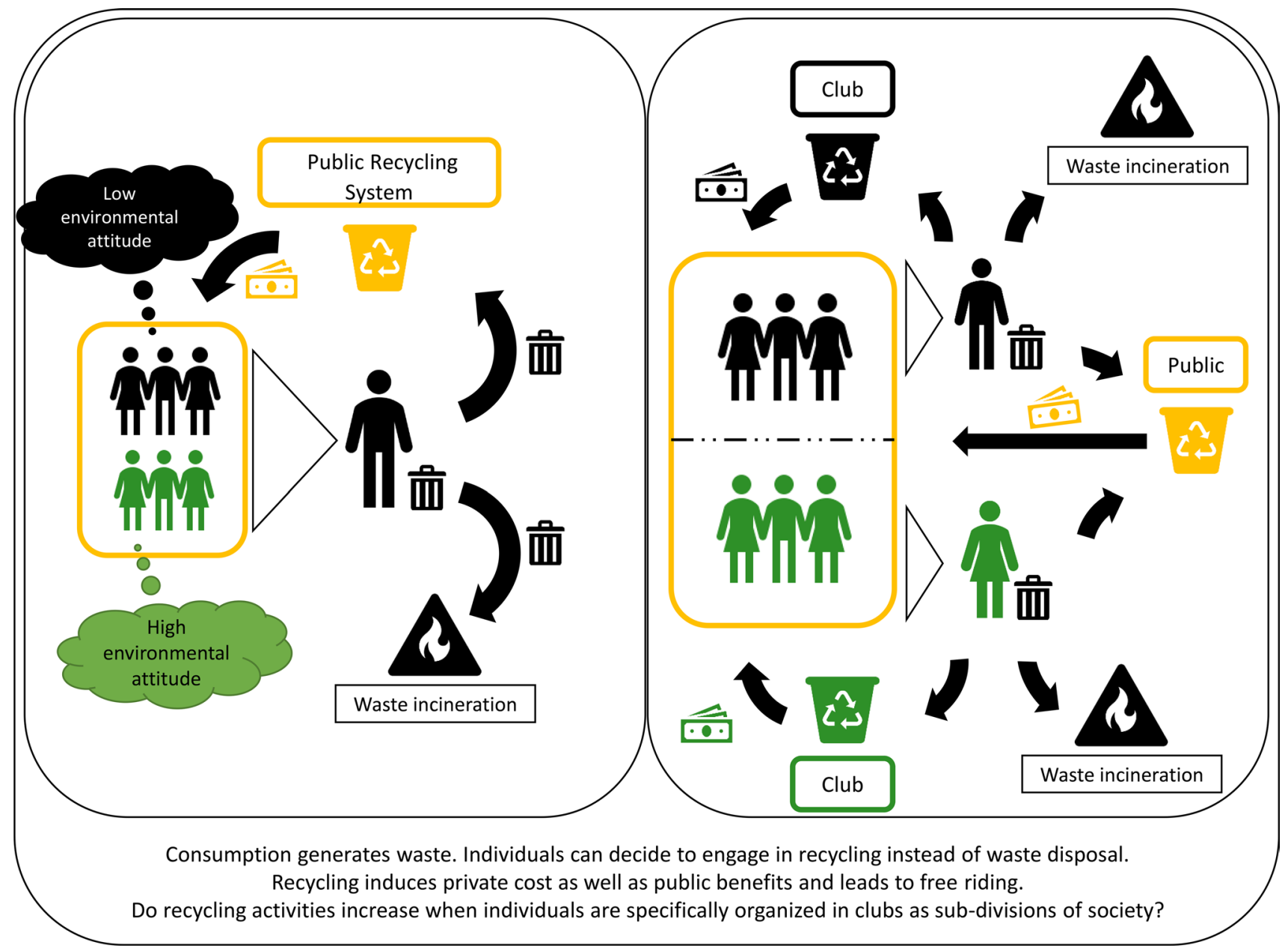

Keywords Experimental economics $\cdot$ Recycling $\cdot$ Recycling policy $\cdot$ External effects $\cdot$ Public goods $\cdot$ Club goods

\section{Introduction}

In recent years, the intensification of industrial recycling activities and the improvement of the associated circular economy networks have become an essential area of environmental policy. Recycling does not only help to reduce the environmental costs caused by waste, but can also be used specifically by industrial policy to reduce certain shortages of raw materials, as in the case of rare elements that are used in mobile phones. In addition, recycling can be used to reduce the carbon footprint of consumption activities, helping to mitigate the required space and emissions from landfills all around the world. In this paper, we use the broader definition of the term "recycling" compared with the narrower one in the European waste legislation. Accordingly, the term comprises all means of how to feed waste from components and materials back into the production and consumption cycle, including all necessary collection, transportation, and treatment steps. Therefore, recycling, in the sense addressed in this paper, includes product and component reuse, use after remanufacturing and second life applications, material and feedstock recycling, as well as energy recovery. The term "discarding" as used in this paper characterizes the least efficient, yet legal, orderly way to get rid of waste in terms of environmental and resource efficiency aspects. A third option not addressed in this paper comprises the more or less illegal ways of littering. The term (legal) "disposal" incorporates all means of how to bundle and transfer public waste streams to legal collection systems and pass these on to elaborated recycling structures, to be transferred down to low-level discarding systems.

From an economic point of view, recycling is not cost free and does not represent a certain kind of a perpetual motion machine which allows to overcome the restrictions 
of the laws of thermodynamics. However, in many cases, it is cheaper and more efficient to recycle the raw materials contained in the products consumed, instead of disposing them in the waste. Even though raising recycling rates is a task of environmental policy, the effectiveness of recycling systems depends on cooperative household behavior. Transferring specific waste streams to elaborated collection and recycling structures may increase opportunity costs for private households by raising the personal effort of informing, reflecting, sorting, and depositing in comparison with collective disposal at the most convenient point.

Economic literature highlights positive externalities in the case of recycling. Households that voluntarily participate in recycling systems also contribute to the internalization of external effects associated with conventional waste management. For at least four decades, recycling-related behavior of private households has been investigated in a large number of empirical studies (such as Kinnaman 2009; Beede and Bloom 1995). These studies, for instance, address the question of which regulatory conditions or which social norms and motives have a positive effect on recycling behavior. Although several papers on recycling behavior marginally consider elements of strategic interaction and mutual influence within peer groups, most of them lack explicit gametheoretical elements where individuals voluntarily contribute to public goods. In this paper, we present an incentivized economic experiment where subjects adopt the role of private households and have various options for recycling and waste disposal. The underlying model treats recycling as a social dilemma situation. Within a society, each recycling decision has positive external effects on all other households. While it is beneficial for the society as a whole if every household is cooperative and involved in recycling as fully as possible, each single household has an incentive to deviate from that kind of cooperation. Moreover, we give households the opportunity not only to participate in large public recycling systems, but also to contribute to smaller, more exclusive recycling clubs whose members, to a large degree, also share specific environmental attitudes. The contribution of our article is, therefore, the examination of the following two research questions: First, we ask whether the expansion of recycling options leads to an increase in household contributions (at all); second, we investigate whether the different composition of the clubs affects the decisions of their members.

Our paper is organized as follows: The second section presents a short overview of the empirical literature on the recycling behavior of private households. In the third section, we discuss the suitability of the club good model for an experimental investigation of recycling behavior. The fourth section entails a description of the experimental design we employ and is followed by a presentation of the results of our study in the fifth section. The last section offers a summary of the main observations and derives some conclusions with respect to the design of further research.

\section{Recycling behavior of private households}

\section{State of the theoretical and empirical literature}

Environmental economics treats recycling as a classic case of market failure. In this respect, there are external effects that differ from public goods only in terms of their aggregation to the optimal quantity. The generation of waste can be interpreted as a by-product of private consumption and production activities inducing costs for the whole society, which are not incorporated in market prices. Over the last three decades, economists have investigated different institutional arrangements of how to organize recycling systems on governmental or municipal levels and emphasized the external cost argument for legitimizing such a type of market intervention. Empirical estimates of external costs of the disposal of different types of solid waste are used for analyzing costs and benefits of certain recycling systems (Kinnaman 2009; Beede and Bloom 1995). According to environmental economics textbooks, recycling problems, when regarded as problems of external effects, can be solved by applying environmental policy instruments such as deposit systems. Suboptimal recycling rates can even be raised to optimal levels if the "true" level of external costs is known (Tietenberg and Lewis 2014). However, taking into account that perfect information of environmental regulators is not realistic to assume, and that perfect knowledge about consumer behavior is not available, things become more complicated. Environmental policies directed at increasing recycling rates in the economy are strongly reliant on cooperative behavior of private households as private waste management activities cannot be monitored or regulated directly without imposing massive regulations on all citizens.

There is a bulk of empirical literature on household behavior in the recycling case which has grown over the last decades. In a recent survey, Briguglio (2016) analyzes empirical papers that investigate conditions and regulatory approaches that potentially stimulate household cooperation in the case of recycling. Briguglio shows that, more recently, the focus of empirical literature has shifted from analyzing theoretical models of waste production (including illegal disposal and recycling) to behavioral and psychological theories of altruism, moral behavior, and social preferences.

Trudel (2019) suggests that the psychological factors that influence recycling behavior can be divided into four areas, namely cognitive barriers, the self, social influence, and product characteristics. Certain product characteristics, for example, might give rise to behavioral effects in the case of recycling. It can be shown that distorting 
products from their original form, e.g., by cutting them up, leads to less recycling activities as compared to recycled products that have kept their original design (Trudel et al. 2016). Among others, Schultz (1999) and Barr (2007) investigate recycling behavior from the perspective of social psychology. Schultz (1999) shows that voluntary participation and individual contributions in recycling programs can be extended if the social environment of the individual household allows for group feedbacks which interact with personal norms. The results of Barr (2007) suggest that a certain mix of subjective environmental attitudes, situational characteristics, and psychological factors can be used to explain recycling behavior. However, in contrast to household behavior in the field of waste reduction or private reuse of materials, which can be explained merely by subjective knowledge or concern-based factors, recycling behavior has to be interpreted as a "highly normative behavior." This conclusion is also supported by a study of Cecere et al. (2014) which investigates the interplay of extrinsic and intrinsic motivation in the case of private households' waste management activities. Cecere et al. distinguish between waste reduction and recycling, and show that the behavior of households in reducing their waste can hardly be explained by social or group-oriented motives as it is not an observable action. Rather, it can be linked to purely altruistic motives. Against this backdrop, extrinsic motivation associated with social norms, imitative behaviors, and peer pressure are important for recycling activities, because they are visible in society and are, for example, open to reciprocity considerations. Indirectly, they support the standard hypothesis mentioned above, namely that recycling activities which are not driven by intrinsic motivation can be incentivized by economic instruments (such as taxes, levies, or deposit systems). Interestingly, there are several papers such as Kaoursakis and Birol (2008) which state that while there is a general public acceptance for introducing incentiveoriented instruments, households prefer the introduction of deposit refund schemes rather than unit-pricing programs or pay-as-you-throw schemes.

The role of social norms and warm-glow elements of altruistic behavior in the case of recycling is also highlighted by Abbott et al. (2013). They conclude that economic incentives should not be used as a substitute but rather as a complement for intrinsic values. Social norms and groupinduced effects play a greater role than subjective environmental attitudes. At the same time, their results refute an influence of warm-glow motifs. Politicians might therefore rely on social norms rather than influence behavior directly. These results also underline the importance of decentralized, supply-side activities such as kerbside collection, which makes the participation of individual households more visible to their neighborhood.

\section{Research gap}

Other studies such as Brekke et al. (2010) investigate strategic interactions of individuals and highlight the public good feature of individual recycling decisions. They start by questioning why individual contributions to recycling systems are increasing in contributions of other individuals, as reported in several studies. Similar to other cases of environmentally friendly behavior of consumers, such as green electricity (Menges et al. 2005), Brekke et al. (2010) ask whether contributions of other individuals affect individual donations as complements or as substitutes. The authors contrast impure altruism to individuals' duty orientation when contributing to glass recycling systems. The hypothesis of duty orientation states that individuals driven by external norms and duties interpret behavior of other people as an indication of their own responsibility to participate. Brekke et al. (2010) point out that the concept of responsibility feelings, which are somewhat unusual in economics, is related to the behavioral concept of reciprocal preferences, which is well documented in experimental economics (see Fehr and Gächter 2000; Hoffman et al. 1998). On the other hand, impure altruism and warm-glow motivation are described by pure pleasure motivation and less by social interaction. The empirical results of the study on recycling behavior reported by Brekke et al. (2010) point to strong social interaction effects which can be linked to the attribution of responsibility. Households who firmly believe that their recycling attitudes are shared within their group derive a greater sense of responsibility from these attitudes. According to Brekke et al. (2010), this observation is in line with the hypothesis that duty and responsibility cannot be interpreted as exogenous factors when analyzing preferences. Households derive conclusions about their own responsibility by observing other households. Although such a type of responsibility constitutes a burden, households are willing to accept this burden and to engage in recycling if the duty is indisputable. Brekke et al. (2010) conclude that policy approaches such as public campaigns for recycling have merely a stimulating effect if they change the perception of what others are doing.

Further authors describe the connection between recycling and the theory of public goods. Rompf et al. (2017) point out that institutional trust can counteract the inhibitory effect of individual costs on cooperation in a collective action dilemma, using recycling as an example. Huhtala (2009) finds a negative income effect on the willingness to pay for recycling, but a positive income effect on the willingness to pay for more convenient incineration of waste. This raises distributional issues, since poorer households make comparatively greater efforts to behave in an environmentally sound manner.

Another approach worth mentioning is the method of "Identity Economics," which was presented by Akerlof 
and Kranton (2000) and whose relevance was recently underlined by economists such as Foss (2019) and Collier (2019). Akerlof and Kranton (2000) incorporate the factor identity into the economic behavioral model. They assume that societies consist of different social categories that share certain norms. Using a simple game-theoretic model, they show that members of social categories are inclined to reduce deviations from these norms and adapt their behavior accordingly. From an economic perspective, further investigation of these considerations, e.g., with respect to recycling, seems promising.

Summed up, numerous empirical studies reveal factors influencing recycling behavior. Although many highlight social interaction phenomena of household behavior when people contribute to public goods on a voluntary basis, strategic elements of individual behavior in the case of recycling situations have not been considered in the literature so far. Therefore, we make a first attempt to investigate interaction effects in different institutional settings to determine which role can be ascribed to individual environmental attitudes. The experimental design and the hypotheses which are tested are drawn from the model which is presented in the next section.

\section{Model}

\section{Recycling in a public good framework}

The starting point of our model is as follows: Voluntary participation and individual contributions to a recycling system entail positive externalities for the whole society. This structure allows for modeling a public goods game. A recycling system can, by definition, be treated as a public good: Its output (such as the avoidance of garbage and the protection of scarce resources) is represented by the sum of voluntary individual contributions. However, its benefits are also accessible to members of the society who have not participated in the provision (recycling process). Given certain assumptions, this formal model can be solved with respect to individual utility maximizing behavior (Nash equilibrium) and its social optimum (welfare maximization). In its simplest version, the model can be represented as follows (Ledyard 1995): Assume that a society consists of $N$ households. Each single household $i$ has an endowment of $m_{i}$ which is used for consumption. We assume that consumption generates waste one by one. Hence, each household has to derive a decision on how to manage $m_{i}$ units of waste. The household can contribute $g_{i}\left(0 \leq g_{i} \leq m_{i}\right)$ units of its waste to a public recycling system. The payoff $u_{i}$ each household realizes from this decision is determined by the following equation: $u_{i}=\left(m_{i}-g_{i}\right)+a \sum_{j=1}^{N} g_{j}$

The opportunity cost of contributing to the recycling system (e.g., due to inconvenience) is normalized to one per unit. Alternatively, waste can be dumped to trash cans (which is usually the case for mixed residual waste) without any direct or immediate cost. The benefit realized per unit of $g_{i}$ is set to $a$. Hence, the marginal per capita return (MPCR) of contributing to the public recycling system is $a$ (with $0<a<1<N a$ ) and represents the gap between individual utility maximization $\left(g_{i}=0\right)$ and the Pareto-efficient social optimum $\left(g_{i}=m_{i}\right)$ which is driven by positive externalities. Hence, the question arises of how to close this gap and to overcome such a kind of market failure.

The empirical literature reported in the previous section also discusses the issue of varying the supply-side of public recycling systems in several dimensions, such as its opportunity cost structure (e.g., convenience effects of kerbside versus non-kerbside systems) or the number of resources and materials collected. There are several papers (such as Kaoursakis and Birol 2008; Abbott et al. 2017) that investigate how households' willingness to contribute reacts to such supply-side variations.

\section{Simultaneous provision of public goods and club goods}

In our model, we also vary the supply-side of recycling systems by introducing an additional feature. Public recycling systems can also be organized as club systems. The most important difference between a public good and a club good lies in the exclusion principle: While the benefits jointly generated in club goods are accessible to all members of the club, they are not accessible to all other members of society. From an economic perspective, this exclusion principle gives rise to an interesting point: Although the same problem of cooperation arises within the boundaries of the club as with public goods (e.g., free riding), the members of the club can better protect themselves from noncooperative behavior by virtue of the exclusionary principle. This potential feature of club goods is related to the results of Brekke et al. (2010) obtained from a survey of households' glass recycling activities in Norway. They show that households that are aware of sharing recycling attitudes within their peer group derive a greater sense of responsibility and contribute more to the recycling system. This observation is in line with the general hypothesis of Mancur Olson (1965): Commonly shared goals face organizational problems in large groups when individuals perceive only limited relevance of their actions. Therefore, adding elements of excludability and 
selective "private" benefits become an important strategy to overcome this social dilemma.

The importance of an exclusion mechanism of clubs is also emphasized by Cornes and Sandler (1996). Therefore, it can be necessary to exclude individuals who do not invest in the club's purpose in a satisfactorily manner in order to prevent free riding. However, the introduction of the club good with its theoretical exclusion possibilities does not represent a change in the material incentive structure in this model. Firstly, there is still the possibility of investing in the public good and, secondly, the attraction of free-riding in the club good context remains in the same form. The introduction of the club good hence represents a change in the social context of the interaction of individuals within a predetermined society. We are thus taking up a central idea in the field of the so-called Identity Economics (Akerlof and Kranton 2000). According to this theory, it is not questioned whether the individual behavior can be explained by cost/ benefit calculations. However, the influence of these motives can be changed by the social context in which individuals act and see themselves as part of a group. It is a well-known result in the experimental literature that individuals tend to treat their counterparts more kindly if they themselves are treated kindly by them (Rabin 1993).

The empirical literature on club goods is somewhat limited in experimental economics. Although individual decisions in such types of public good experiments are mostly framed as charitable giving, results can also be interpreted in a general manner or with respect to the recycling case. Chakravarty and Fonseca (2017) show that cooperation and the overall contribution of individuals substantially increase when they are offered an additional group-specific investment opportunity. However, these efficiency gains take place only when the expected financial returns to the club good are at least equivalent to the public good. An experiment by Blackwell and McKee (2003) identifies two drivers of individual contributions to club goods and public goods when investment opportunities are offered simultaneously. Contributions to the group-specific good are characterized by reciprocity as they increase with past contributions of other group members. The allocation of spending for the club good and the public good is affected by the respective MPCR. The standard result of experimental economics posits that some level of cooperation in public good environments still exists but decreases from period to period. Quite interestingly, it can be rejected for the club good investment as in Blackwell and McKee (2003) where it does not decrease over time. An experiment by Cherry and Dickinson (2008) suggests that there is a general tendency that cooperation and total contributions increase when individuals are offered multiple sets of alternative public goods. Chen and $\mathrm{Li}$ (2009) show that the generation of group identities in such kind of experiments can have a large impact on social preferences, for instance by reducing envy effects. Several studies investigate constitutional effects of group identities, such as natural identities (Chen et al. 2014) or gender (Brown-Kruse and Hummels 1993), which might give rise to conditional, group-specific altruism.

The public good model (1) can easily be supplemented with an additional club good opportunity. Assume that the society can be divided into two distinct subgroups with an equal number of households $N / 2$ and that each household $i$ also has the opportunity to invest $k_{i}\left(0 \leq k_{i} \leq m_{i}\right)$ units of their waste to a group-specific recycling system. The return of this investment and its MPCR is represented by $b$ (with $0<b<1<(N / 2) b$ ). The payoff of the waste management decision of household $i$ can be expressed as:

$u_{i}=\left(m_{i}-g_{i}-k_{i}\right)+a \sum_{j=1}^{N} g_{j}+b \sum_{l=1}^{N / 2} k_{l}$

As in (1), in line with economic standard theory, utility maximizing behavior by choosing $g_{i}$ and $k_{i}$ predicts that $g_{i}=k_{i}=0$ (Nash equilibrium). On the other hand, the Paretooptimal solution recommends maximum contributions of all individuals. If $a=b$, the welfare solution is indifferent to different allocations among $g_{i}$ and $k_{i}$, as long as $g_{i}+k_{i}=m_{i}$. However, if both goods have the same MPCR $(a=b<1)$, then different group sizes might induce a different return on the investment if and only if specific fractions of other members are expected to contribute as well. While some authors argue in line with Olson (1965) and assume decreasing average contributions for an increasing $N$ in public good games, Ledyard (1995) reports several studies on group size effects, indicating that the public good is potentially more attractive as it has a larger number of potential contributors. For large groups with ten players and small groups with four players, Isaac and Walker (1988) show that for a small MPCR, average contributions to the public good are higher in the large groups and that for a large MPCR there is no clear effect of group size. In order to compensate for this group size effect, we choose an approach suggested by Chakravarty and Fonseca (2017) and Blackwell and McKee (2003) and normalize the MPCR as follows: $a N=b(N / 2)$ which is equal to $2 a=b$. This approach is also in line with the concept of the effective average per capita ratio (APCR) which is ( $a$ $N) / N$ for the public good and $b(N / 2) / N$ for the club good. Whereas the MPCR to the individual is $a$ in the case of the public good and $b$ in the case of the club good, the APCR divides the total return of investing one unit by all members of the society. Although, from a marginal perspective, it is clear that this return of the club good is actually not distributed among all members of society, it is established as useful behavioral concept for comparing the relative payoffs with the group and the public good (Blackwell and McKee 2003). Note that if $a N=b(N / 2)$, the Pareto-efficient welfare 
optimum can include different allocations among $g_{i}$ and $k_{i}$, as long as $g_{i}+k_{i}=m_{i}$.

Applying this club good structure (2) and its intergroup competition to the recycling case also implies introducing an element of institutional competition of different recycling systems on the supply-side. As an alternative to free waste disposal, each household has two recycling systems at its disposal: A system that can be used for the economy as a whole and a certain closed-shop recycling system, where access and benefits are exclusive to members. In reality, private households, for example, have access to municipal recycling yards and collection points which offer their services exclusively to citizens of the municipality on the basis of public fee schedules. An example of such a disparate benefit could be that the improved recycling efforts of club members result in a cost reduction of the public fee structure due to a better utilization of recycling capacities. At the same time, households can often hand over their waste to other commercial traders, who then collect it throughout voluntary collections. In addition, recycling also takes place in the course of take-back obligations of commercial trade.

In our experiment, two types of recycling systems are modeled as the public good and the club good. In both recycling systems, monetary incentives are identical, e.g., contributing one unit to the public good or the club good reduces the own payoff by one unit but increases social welfare (measured as the sum of $N$ payoffs) by $2 a=b$.

\section{Experimental design}

\section{Treatment structure and procedure}

Since this recycling experiment forms part of a larger interdisciplinary research project on sustainable household behavior, it serves to identify key points for longer-term future investigations. The pilot reported in this paper consists of two treatments: In order to test for the relevance of the club good structure, the first treatment (treatment 1) refers to the public good model (1) and the second treatment (treatment 2) is based on the club good model (2). The experiment was conducted as a classroom experiment with 36 undergraduate students during an economics course at the Clausthal University of Technology in Germany on 16 July 2019. Table 1 provides an overview of the experimental design.

For the experiment, we used classEx software (Giamattei and Lambsdorff 2019) and a within-subjects design. This means that participants are exposed to both treatments, one after the other, and each participant serves as his or her own baseline. A main advantage of this design is that it may reduce the variance of unobserved components, thereby increasing the precision of the estimated
Table 1 Experimental design

\begin{tabular}{lll}
\hline Treatment & Treatment 1 & Treatment 2 \\
\hline Public good MPCR & 0.3 & 0.3 \\
Club good MPCR & - & 0.6 \\
Endowment (waste units) & 10 & 10 \\
Number of rounds & 10 & 10 \\
Number of societies & 6 & 6 \\
Subjects & 36 & 36 \\
\hline
\end{tabular}

average treatment effect. As compared to other design options, fewer subjects have to be recruited (List et al. 2011; Czibor et al. 2019). Moreover, the nonparametric tests used in the following sections work well with our sample size. We designed a repeated game over ten rounds per treatment. This approach enables us to take learning effects into account (Ledyard 1995) and corresponds to reality because waste disposal decisions have to be made repeatedly. However, due to organizational limitations of the software, we are not able to control for sequence effects. For further experiments, we will switch to a more appropriate between-subjects design. The experiment took $45 \mathrm{~min}$, and the exact procedure can be summarized as follows:

- Subjects were informed that in the experiment, they would adopt the perspective of households which had to decide about their waste disposal. They were also informed that the task was to decide on the use of an initial endowment. A monetary amount reflecting the results of these decisions would be paid out in cash on the basis of a lottery at the end of the experiment (see later section).

- After connecting mobile devices to the server, participants underwent a questionnaire with respect to certain environmental attitudes which were used for later group separation (see later section).

- Subjects were told that they had been randomly assigned to a society of six households altogether and that the composition of this society would remain unchanged throughout the experiment. They were also informed that they did not know the other households with which they formed a society and that there was no way to communicate with them (stranger design).

- Thereupon, printed instructions for treatment 1 were handed out, and-after they were read by the participants - the corresponding game was played.

- After finishing the final round of treatment 1, participants were informed about the formation of the clubs within their society. They were assigned to "club 1" or "club 2," each consisting of three households. Then, a so-called slider-game was played where the different clubs com- 
peted against each other (identity reinforcement, see later section).

- Once again, instructions were handed out, and the second treatment (treatment 2) was conducted.

- The experiment ended after collecting some demographic data.

- Finally, participants received their payment according to the lottery mechanism (incentive mechanism, see later section).

\section{Instructions and framing}

By reading the instructions for treatment 1, participants are introduced to the following situation: Every participant adopts the role of a single household which is part of a society of six households. Each household of this society is endowed with ten tokens in each round which are used for consumption. When consuming, waste is generated and has to be disposed. Two options are offered: Ten units of waste can be disposed either as conventional household waste with no additional costs or in a public recycling system. For every unit of waste which is brought to this recycling system, one token has to be paid. Due to positive externalities of recycling, each recycled unit generates a benefit of 0.3 tokens for all six members of the society, as expressed in (1). The decision has to be made repeatedly in ten consecutive rounds. After each round, each player is informed about the investments and payoffs of all members of his or her society.

The instructions for the subsequent treatment 2 pick up from the previous framing of recycling opportunities but introduce an additional disposal option as suggested in Eq. (2): Alongside with the possibilities known from treatment 1, the ten units of waste can also be recycled in a system that is only accessible for its three club members. Again, costs to dispose waste in this system are one unit per token, while the benefit of 0.6 tokens per recycled unit is reserved for the three club members. Participants were aware that both recycling options are similarly attractive with respect to their social returns, because $6 \cdot 0.3=3 \cdot 0.6$. As before, this decision has to be repeated ten times. The structure of the decision screen is presented in the appendix.

\section{Introducing and enforcing group identity}

Adapting the club good model (2) to the recycling case in the context of a laboratory experiment involves the question of how to design a meaningful grouping variable which can be used to split a society of $N$ subjects into nonoverlapping groups. The experimental design of the few club good experiments reported in the literature follows the so-called minimal group paradigm. In these approaches, subjects are grouped by asking them to solve simple tasks such as evaluating paintings (Chakravarty and Fonseca 2017; Chen and
Li 2009) or by exogenously assigning subjects to different colors (Blackwell and McKee 2003). An artificial group identity is created that is not at all related to the substantive focus of the choices made in the later experiment. Although subjects were able to communicate during the stage of group formation, these papers assume that the group identity is independent of uncontrollable social interaction effects that could influence the behavior of individuals within and outside the group.

In our experimental design, we change the artificial quality of group identity and link group identity more closely to the tasks individuals have to solve in the experiment. Moreover, we indirectly motivate individuals to draw conclusions about common values and social preferences shared in their group. This stands-for example-in contrast to the philosophy of group formation as used in Chen and $\mathrm{Li}$ (2009), where an individual group member cannot draw conclusions about the pro-social preferences of his or her group members (and the members of the other group) following the process of group formation and later in the experiment. We use the attitudes expressed by individuals on environmental and recycling issues for grouping them in order to test whether commonly shared values influence individual behavior. As recycling activities lead to reduced human impact on the environment, similar environmental attitudes should become a common ground of every club. The process of group formation and group identity reinforcement which subjects went through in the experiment can be summarized as follows:

- At the beginning of the experiment, participants were asked to complete a questionnaire consisting of ten questions (see appendix). Items were obtained from Fernández-Manzanal et al. (2007) and adapted to our purpose. For every question, participants expressed their attitude toward the environment on a 6-point Likert scale. It is important to note that the subjects were unaware that we would use this information for later grouping.

- After playing treatment 1, the group formation took place. The answers to the ten different questions were aggregated to an average index in order to rank all $N$ society members accordingly and split societies into clubs of N/2 members with "club 1" in which all members appreciate the environment at least as much as any member of the other "club 2."

- Subjects received three pieces of information: First, they were informed of being part of a club with all members having similar attitudes toward the environment. The denomination of both clubs ("club 1" or "club 2") was chosen to be neutral. Second, they were informed about the index of their own environmental attitudes as stated at the beginning of the experiment. And third, they were also notified about the average index of the members 
of the society they were assigned to. Consequently, the group membership was not explicitly mentioned, but could be derived from the given information.

- In order to stimulate the feeling of belonging together, the clubs competed in a slider-game. The task of the club members was to realize as many as possible proper slider settings within a minute. In each society, two clubs competed against each other. The members of the winning club received a potential extra payment, paid out at the end of the experiment. Information on whether the own club won was revealed directly after the slider-game.

\section{Incentive mechanism}

In both treatments and after every round, the individual contributions to the recycling system of all players of the group, as well as their payoff, were communicated on the screen (see appendix). The experiment was incentivized by a random lottery mechanism. Subjects were told that at the end of the experiment all six members of one randomly selected society would receive the payoff they achieved in a randomly selected round, with one token equaling 1 EUR. In total, 178.80 EUR were paid out: 96.00 EUR in treatment $1 ; 76.80$ EUR in treatment 2, and 6 EUR in the process of identity reinforcement. On average, every participant received 4.97 EUR for participating in the experiment.

\section{Hypotheses}

The experimental design described above focuses on two research questions: The first question relates to potential effects of introducing a multiple institutional designs in the case of recycling as opposed to a pure public good structure. The social return to both types of investment options is the same. However, such kind of financial equivalence disregards expectation formations about the behavior of other subjects. Assuming that there is uncertainty about the behavior of all other players, investing in the club good might become more attractive due to the larger MPCR. The second question is directed to possible in-group effects when clubs discriminate between certain attitudes. More specifically, we investigate whether there are possible group effects if the composition of the groups is based on similar environmental attitudes of their members as suggested by Brekke et al. (2010), who identified a certain peer group effect. We explicitly assume that participants with stronger environmental attitudes have stronger pro-social preferences and therefore contribute higher shares of their endowments. Hence, our hypotheses can be expressed as follows:

- Hypothesis 1 The sum of individual contributions to recycling systems increases when several alternatives are offered.
- Hypothesis 2a The contributions to the club good are higher in the club whose members share stronger attitudes toward the environment.

- Hypothesis $2 \mathbf{b}$ The total contributions (i.e., the sum of contributions to the club good and the public good) are higher in the club whose members share stronger attitudes toward the environment.

\section{Results}

The results section is structured as follows: After first presenting the more general descriptive results and second analyzing the composition of the clubs, we turn to the implications of the previously formulated hypotheses. In contrast to the instructions, we follow the economic language and henceforth speak of public goods (PG) and club goods (CG).

\section{Descriptive results}

Table 2 provides an overview of the average contributions to the PG, the CG, and total contributions as well as average payoffs. Results are separated by treatment and round: The values for round 1 represent average contributions and payoffs of all participants in the first round only, while the values for round 1-10 refer to average contributions of all participants in all rounds. Results show that in treatment 1 , participants contributed $38 \%$ of their endowment to the recycling system, generating an average payoff of 13.04 EUR per round. In treatment 2, total contributions (44\%) and payoffs (13.52 EUR) are higher as almost $68 \%$ of contributions are made using the CG. Except for the public good in treatment 2 , average contributions in the first round exceed the mean of all ten rounds and indicate a decreasing trend over time.

Figure 1 allows for a closer examination of total contributions in both treatments. It has to be kept in mind that using the within-subjects design, all players play treatment 2 after having played treatment 1 . In round one, total contributions

Table 2 Average contributions and payoffs and standard deviations

\begin{tabular}{llllll}
\hline Treatment & \multicolumn{2}{l}{ Treatment 1} & & \multicolumn{2}{l}{ Treatment 2} \\
\cline { 2 - 3 } \cline { 6 - 6 } Round & 1 & $1-10$ & & 1 & $1-10$ \\
\hline PG contributions & 4.25 & 3.80 & & 1.22 & 1.41 \\
& $(3.57)$ & $(3.00)$ & & $(1.90)$ & $(1.94)$ \\
CG contributions & - & - & 3.89 & 2.99 \\
Total contributions & 4.25 & 3.80 & & 5.11 & 4.40 \\
& $(3.57)$ & $(3.00)$ & & $(3.62)$ & $(3.28)$ \\
Payoffs & 13.40 & 13.04 & & 14.09 & 13.52 \\
& $(3.55)$ & $(2.79)$ & $(3.41)$ & $(2.83)$ \\
\hline
\end{tabular}

Standard deviations in parentheses 


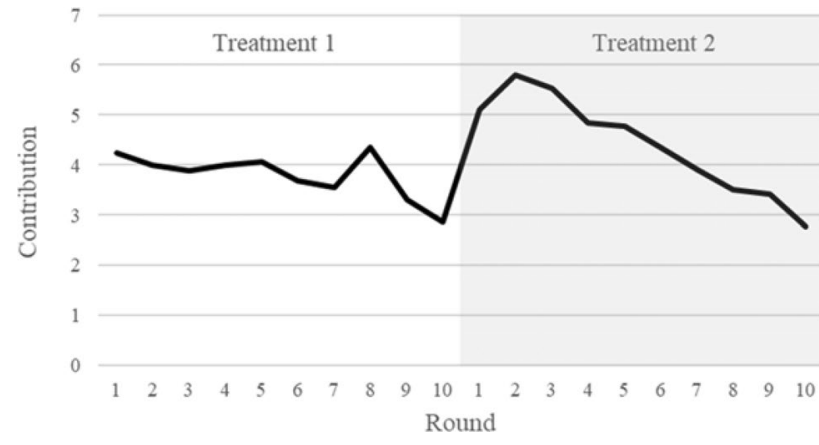

Fig. 1 Average total contributions in both consecutive treatments

are slightly lower in treatment 1 than in treatment 2 (4.25 versus 5.11 units). A tendency of decreasing contributions with a minimum of about 2.8 units in round ten can be observed for both treatments. In treatment 2 , the average total contributions of participants to recycling systems over all rounds are about $16 \%$ higher (4.40 units) than in treatment 1 (3.80 units). Yet, the curve progressions are rather similar and declining-a standard result in public good experiments (Ledyard 1995).

\section{Composition of the clubs}

As described above, the allocation to the different clubs is based on individuals' environmental attitude. This was determined by using an average from answers to ten questions (see appendix) using a 6-point Likert scale. The answers ranged from 0 ("Environment is not important at all to me") to 5 ("Environment is very important to me.") The average environmental attitude of members in Club High was 3.67, and 2.08 in Club Low, reflecting a significant difference. Further statistical analyses show no other significant differences regarding the composition of the groups. Using a Chi-Square test, we checked for differences in terms of subjects' gender, income, secondary employment, nationality, and religious affiliation. In the slider-game, which was conducted between the two treatments, members of Club High solved an average of 3.77 out of 10 tasks right, while Club Low received a similar result of 3.22 correct answers. Furthermore, the age of the undergraduate students does not differ considerably.

\section{Testing hypothesis 1}

Figure 1 depicts the overall contributions of both treatments over time. Bearing in mind that the order and financial attractiveness of contributions are similar in both treatments, this graph reveals interesting results. Instead of continuing a declining trend after treatment 1 , the overall contributions surge to a new maximum level in the first round of treatment
Table 3 Comparison of contributions across treatments and clubs

\begin{tabular}{llll}
\hline & Club High & Club Low & All \\
\hline Total contributions in Treatment 1 & 4.08 & 3.52 & 3.80 \\
& $(3.05)$ & $(3.15)$ & $(3.10)$ \\
Total contributions in Treatment 2 & 5.51 & 3.29 & 4.40 \\
& $(5.00)$ & $(2.95)$ & $(4.25)$ \\
Wilcoxon Sign-Rank & $p=0.006$ & $p=0.421$ & $p=0.112$ \\
\hline
\end{tabular}

Median in parentheses

2. The peak is reached in round 2 where 5.8 out of 10 units are contributed to both goods. After that, contributions decrease again.

For a statistical analysis of differences in contributions between the two treatments, we use the Wilcoxon Sign-Rank test and define the threshold of statistical significance as $p=0.05$. This nonparametric test is used due to the absence of normally distributed values (e.g., due to differences between mean and median values as shown in Table 3) and since it is applicable to small sample sizes. The test compares participants' contributions in the respective rounds of both treatments to check the equality of the central tendencies. Table 3 provides the results of this test for all participants as well as separated by the clubs. Although participants were not aware of the separation into two clubs during the first treatment, their contributions can be traced back and evaluated ex-post.

Results show that hypothesis 1 , which predicts an increasing sum of individual contributions to a recycling system after offering several alternatives, cannot be proven true for all rounds and participants $(p=0.112)$. A closer examination shows significant differences for the first three rounds only (round 1: $p=0.048$, round 2: $p=0.002$, and round 3: $p=0.007)$.

Nonetheless, we find meaningful results when differentiating between the different clubs. Contributions of Club High members significantly increase in treatment 2 compared with treatment 1 ( $p=0.006)$, while no significant differences can be shown for Club Low. At this point, we refer to the relevance of the composition of the two clubs which will be discussed in more detail later.

\section{Testing hypotheses 2}

The second hypothesis asks about possible differences in the subjects' behavior in relation to their association with the clubs in treatment 2 . Unlike in treatment 1 , the subjects now know that they have been assigned to a club according to their environmental attitude and have their additional $\mathrm{CG}$ recycling option. As this comparison is based on a between-subjects level, the hypothesis is tested by using the nonparametric Mann-Whitney U criterion. Again, 
this test tends to be a good option in the absence of normally distributed values and is applicable to our sample sizes. We define the threshold of statistical significance as $p=0.05$.

Table 4 allows for a comparison of average contributions and payoffs in both clubs in treatment 2 in order to test hypotheses 2. Results show that Club High members made significantly higher contributions to the CG than Club Low members in treatment $2(p=0.012)$. Hence, these results support hypothesis $2 \mathrm{a}$. Regarding hypothesis $2 b$, stating that total contributions are higher in Club High, the results are not so clear: Despite differences in the total contributions of the two clubs, the Mann-Whitney U test results in $p=0.059$ and does-though marginally-not attest a significant increase. Overall, Club High members realized significantly higher payoffs as compared with Club Low members in treatment $2(p=0.037)$. Besides, no significant differences in the two clubs' contributions to the PG and, more interestingly, to the PG in treatment 1 can be detected (see gray bottom of Table 4).

A further impression of the composition of the contributions over the rounds can be obtained by consulting Figs. 2 and 3. They show that the contributions to the PG are rather stable and do not differ significantly for the two clubs (Mann-Whitney U: $p=0.938$ ). Differences in the total contributions are thus mainly caused by contributions to the CG. Furthermore, the decreasing contributions in the second treatment — in contrast to the first—are mainly due to contributions to the CG. Reasons for this different contribution behavior can therefore be linked to the different club compositions.

Table 4 Comparison of contributions and payoffs in Club High and Club Low

\begin{tabular}{llll}
\hline & Club High & Club Low & Mann-Whitney U \\
\hline Treatment 2 & & & \\
PG contributions & 1.39 & 1.44 & $p=0.938$ \\
& $(0.35)$ & $(0.30)$ & \\
CG contributions & 4.12 & 1.86 & $p=0.012$ \\
& $(3.95)$ & $(1.30)$ & \\
Total contributions & 5.51 & 3.29 & $p=0.059$ \\
& $(5.00)$ & $(2.95)$ & \\
Payoffs & 14.45 & 12.59 & $p=0.037$ \\
& $(13.27)$ & $(12.09)$ & \\
Treatment 1 & & & \\
Total contributions & 4.08 & 3.52 & $p=0.521$ \\
& $(3.05)$ & $(3.15)$ & \\
Payoffs & 12.75 & 13.32 & $p=0.628$ \\
& $(12.73)$ & $(13.15)$ & \\
\hline
\end{tabular}

Median values in parentheses

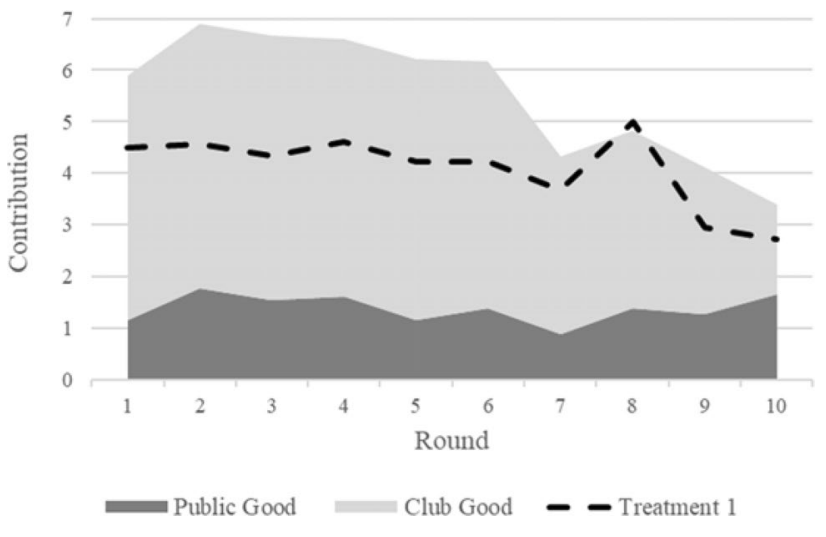

Fig. 2 Contributions to public good and club good in treatment 2 for Club High

\section{Conclusion}

The results of the experiment reported in this paper primarily point to the fact that subjects show a relatively stable degree of cooperation in both consecutive treatments. On average (over all rounds), subjects invested 38\% of their endowment in treatment 1 and $44 \%$ in treatment 2 . At the same time, a standard result of experimental economics which postulates a clear reduction in cooperation from round to round in repeated games (Ledyard 1995) is confirmed in this study. Since both treatments were played in succession (with the same set of co-players in fixed societies) without varying their order, it is of course not unlikely that the round-related decline in cooperativeness also took place across both treatments. However, in an experiment by Andreoni (1988), a public goods game (PGG) is played over ten rounds and then restarted with the same group composition. The restarted PGG is repeated only three times which is, however, not known by the subjects. The results show that the contributions in these three rounds are only minimally lower (a 0.2

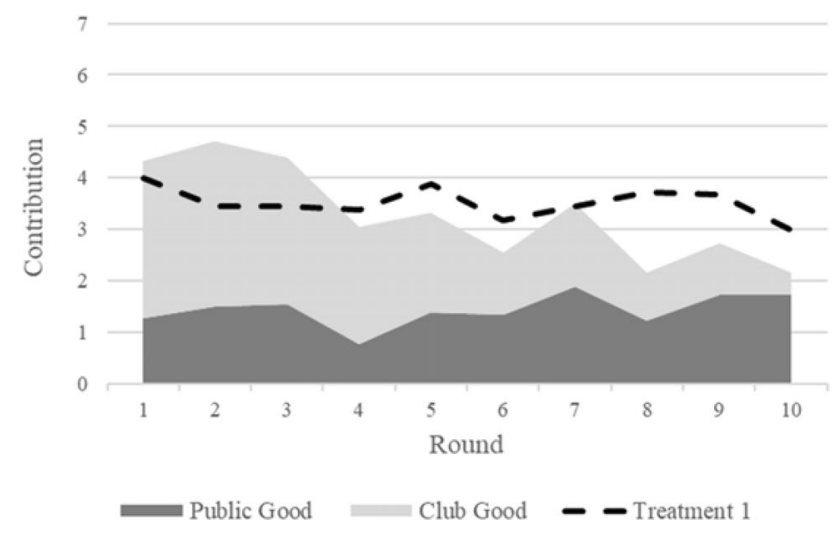

Fig. 3 Contributions to public good and club good in treatment 2 for Club Low 
decline of contributions in round 1 of the restarted PGG) than in the first PGG. In our experiment, there is also no reduction in cooperation when comparing both treatments. There are no statistically significant differences in total contributions to the recycling systems. Against this background, it is surprising that the average total contributions in treatment 2 exceed contributions in the first treatment by $16 \%$. When we consider only the first round of both treatments, the contributions in treatment 2 are $20 \%$ higher compared with treatment 1 . This indicates that by introducing the club good option an activation of cooperation could take place, which potentially counteracts the trend of reducing cooperation in repeated games.

The composition of the clubs in the second treatment, on the other hand, seems to induce a significant effect on individuals' contributions to the recycling system. On average, the members of the club with stronger environmental attitudes (Club High) invested $41 \%$ of their endowment in the club good, while members of the other club (Club Low) only invested about $19 \%$. In Chen and Li (2009), an individual group member cannot conclude the pro-social preferences of his group members (and the members of the other group) through the process of group formation. However, participants in our experiment may assume that stronger environmental attitudes are correlated with stronger pro-social preferences. If a participant is aware of belonging to the group with the lower environmental attitudes, he might assume that the average contributions in his group are lower than that in the group with the stronger environmental attitudes. This would, of course, have an impact on whether he decides to invest in the club good. Although contributions to the club good decrease from round to round, which is common in repeated games, this observation is in line with the result of Brekke et al. (2010). They state that households who firmly believe that their recycling attitudes are shared within their group derive a greater sense of responsibility for participating. An explanation of this experimental group effect could be that it stimulates a sense of belonging, which allows subjects to derive conclusions about their own responsibility. Quite remarkably, contributions to the public good do not differ much between these clubs and do not decrease from round to round.

A complementary explanatory approach can be made with the concept of identity economics from Akerlof and Kranton (2000). In this context, the two clubs represent social categories and their social norms serve as a guideline for the disposal decision. All participants are aware that they have been divided into groups of high and low environmental attitudes and can draw conclusions about which group they are in. Positive recycling behavior tends to be the norm for the group with positive environmental attitudes. This forecast is also reflected in our results: Club Highs' contributions to their CG is higher. At the same time, in the existing dilemma situation, this results in a separation from the other club which is subjected to different norms and thus reflects a different recycling behavior. For policymakers, this implies that relevant standards should be strengthened in all social subgroups.

As described, a central observation of the experiment refers to the total contributions that individuals make to the offered recycling systems. Note that the introduction of the club good option in the second treatment is an extension of the options for action without changing the material incentive structure of the first treatment. The introduction of the additional club good option is therefore merely a change in the social context of the individual decision. However, this variation in the social context led to an increase in the total contributions on average. While the individuals assigned to the respective "Club Low" do not show a statistically significant change in their total contributions, the total contributions of the individuals assigned to the respective "Club High" increase significantly. Therefore, a reasonable policy implication is to localize recycling systems and make their benefits local public goods.

It is difficult to answer whether the results observed in the experiment are due to the creation of exclusion possibilities in the case of club goods, or whether this is rather due to the stronger environmental attitudes of the individuals in Club High. In fact, the influence of these two factors cannot be separated. Environmentally friendly individuals did not behave significantly different from the less environmentally friendly individuals in the first treatment. Statistically significant differences in the behavior of these two groups arise solely in the second treatment with the introduction of the club good option. It is only the change in the social context of individual interactions that leads to the fact that the individuals with stronger environmental attitudes make higher contributions than the individuals with weaker environmental attitudes. In order to discriminate between the two factors "introduction of a club good option and excludability" and "environmental attitudes," we will vary the experimental design in further experiments and test for the influence of alternative grouping variables when introducing the clubs. In addition, future investigations should rather be conducted as between-subjects designs in order to exclude order effects of the treatments. If the groups' influence on the cooperative recycling behavior in future investigations can be substantiated, an interesting extension of these experiments is to include endogenous group processes, for example through elements of gamification.

With regard to the further procedure, the question may be raised whether further insights into individual recycling behavior could also be obtained from simulations instead of experiments. Basically, experiments and simulations represent complementary methods to analyze the connection between individual behavior and social results (Dawid and Delli Gatti 2018). However, the use of (agent-based) simulations is based on concrete assumptions about the structure of individual 
preferences and the decision-making behavior of individuals. Here, deviations from the standard assumptions of microeconomics can be modeled and simulated using stochastic processes as well. The essence of experiments, on the other hand, is that the individual behavior is empirically observed in view of a given incentive structure and is not given exogenously. The question of whether individuals feel motivated to change their behavior in repeated interactions when the social context of interaction is varied cannot be answered with simulations. However, simulation programs can be used to transfer knowledge gained from experiments to other model relationships.

The experiment presented in this paper was initially conceived as a pilot study which aimed to obtain information for the design of a broader study. The results, especially those regarding hypothesis 1 , are to be interpreted with caution, since the design of the experiment did not allow for a variation of the treatment order: This uncontrollable sequence effect is likely to have been at the expense of cooperation in treatment 2. However, the results of the introduction of the club good option turned out to be even more interesting, as this seems to induce a significant effect on cooperation behavior.

Funding Open Access funding provided by Projekt DEAL.

Open Access This article is licensed under a Creative Commons Attribution 4.0 International License, which permits use, sharing, adaptation, distribution and reproduction in any medium or format, as long as you give appropriate credit to the original author(s) and the source, provide a link to the Creative Commons licence, and indicate if changes were made. The images or other third party material in this article are included in the article's Creative Commons licence, unless indicated otherwise in a credit line to the material. If material is not included in the article's Creative Commons licence and your intended use is not permitted by statutory regulation or exceeds the permitted use, you will need to obtain permission directly from the copyright holder. To view a copy of this licence, visit http://creativecommons.org/licenses/by/4.0/.

\section{Appendix}

\section{Questions used for club formation (based on Fernández-Manzanal et al. 2007)}

1. I am willing to consume less and to forgo some comforts if it helps to protect the environment.

2. I am willing to spend more money in order to purchase a recyclable packaging.

3. I like spending time in nature to understand the environment in which I live.
4. I am trying to find out how my behavior influences the environment.

5. If I have to choose between a new highway and a conversation area, I will choose the conversation area.

6. If the public transport system was more efficient, I would prefer it to the car.

7. We should try to conserve plants and animals, even though it is expensive.

8. Environmental education activities for children are important.

9. Our laws should be changed in order to reduce pollution of the environment.

10. Universities should schedule more environmental issues.

\section{Decision screen in classEx (example)}

See Fig. 4.

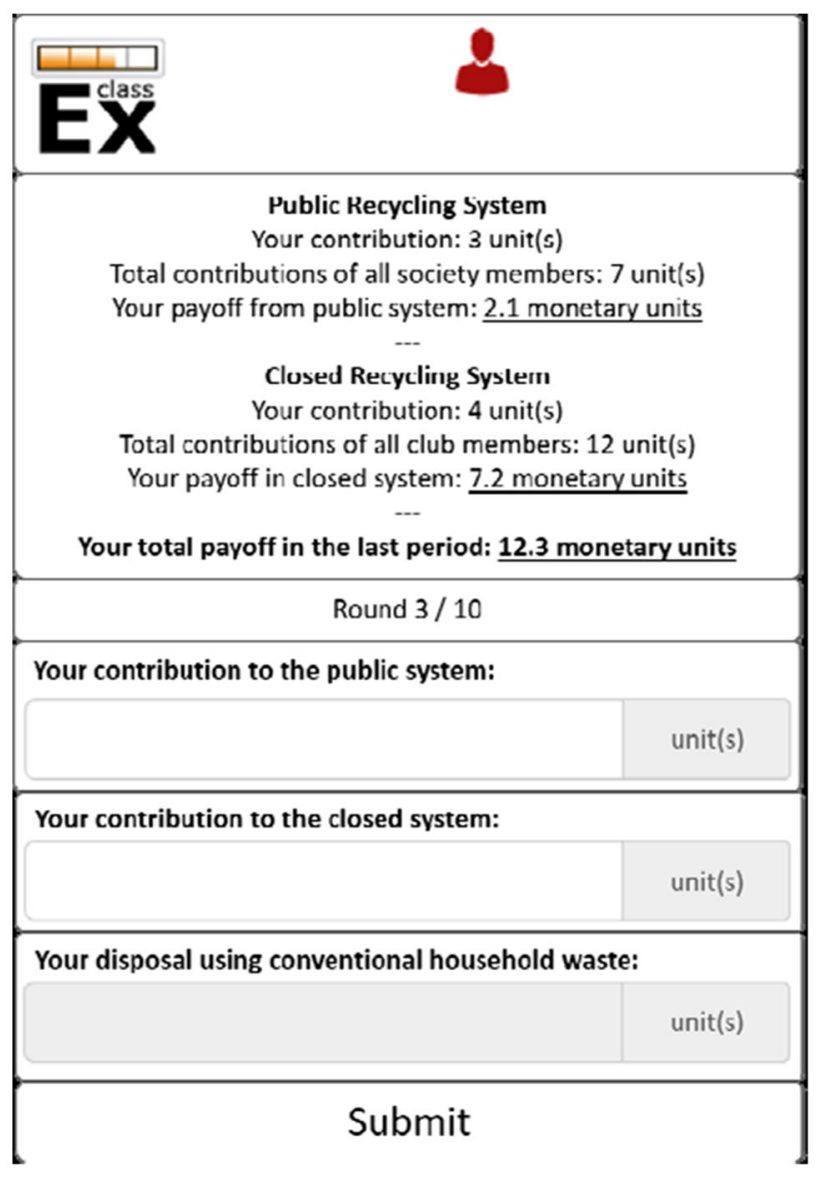

Fig. 4 Decision screen in classEx (example) 


\section{References}

Abbott A, Nandeibam S, O'Shea L (2013) Recycling: social norms and warm-glow revisited. Ecol Econ 90:10-18

Abbott A, Nandeibam S, O'Shea L (2017) The displacement effect of convenience: the case of recycling. Ecol Econ 136:159-168

Akerlof GA, Kranton RE (2000) Economics and identity. Q J Econ 115:715-753

Andreoni J (1988) Why free ride? Strategies and learning in public goods experiments. J Public Econ 37:291-304

Barr S (2007) Factors influencing environmental attitudes and behaviors-A U.K. Case study of household waste management. Environ Behav 39:435-473

Beede DN, Bloom DE (1995) The economics of municipal solid waste. World Bank Res Obs 10:113-150

Blackwell C, McKee M (2003) Only for my own neighborhood? Preferences and voluntary provision of local and global public goods. J Econ Behav Organ 52:115-131

Brekke KA, Kipperberg G, Nyborg K (2010) Reluctant recyclers: social interaction in responsibility ascription. Land Econ $86: 766-784$

Briguglio M (2016) Household cooperation in waste management: initial conditions and intervention. J Econ Surv 30:497-525

Brown-Kruse J, Hummels D (1993) Gender effects in laboratory public goods contribution - do individuals put their money where their mouth is? J Econ Behav Organ 22:255-267

Cecere G, Mancinelli S, Mazzanti M (2014) Waste prevention and social preferences: the role of intrinsic and extrinsic motivations. Ecol Econ 107:163-176

Chakravarty S, Fonseca M (2017) Discrimination via exclusion: an experiment on group identitity and club goods. J Public Econ Theory 19:244-263

Chen Y, Li SX (2009) Group identity and social preferences. Am Econ Rev 99:431-457

Chen Y, Li SX, Liu TX, Shih M (2014) What hat to wear? Impact of natural identities on coordination and cooperation. Games Econ Behav 84:58-86

Cherry T, Dickinson DL (2008) Voluntary contributions with multiple public goods. In: Cherry T, Kroll S, Shogren JF (eds) Environmental economics: experimental methods. Routledge, London, pp 184-193

Collier P (2019) Sir Paul Collier recommends "Identity Economics: How Our Identities Shape Our Work, Wages, and Well-Being” by George A. Akerlof and Rachel E. Kranton. In: Frey B, Schaltegger C (eds) 21st century economics. Springer, Cham, pp 29-31

Cornes R, Sandler T (1996) The theory of externalities, public goods and club goods. Cambridge University Press, Cambridge

Czibor E, Jimenez-Gomez D, List JA (2019) The dozen things experimental economists should do (more of). South Econ J 86:371-432

Dawid H, Delli Gatti D (2018) Agent-based macroeconomics. In: Hommes C, LeBaron B (eds) Handbook of computational economics. Elsevier, Amsterdam, pp 63-156

Fehr E, Gächter S (2000) Fairness and retaliation: the economics of reciprocity. J Econ Perspect 14:159-181
Fernández-Manzanal R, Rodríguez-Barreiro L, Carrasquer J (2007) Evaluation of environmental attitudes: analysis and results of a scale applied to university students. Sci Educ 91:988-1009

Foss NJ (2019) Nicolai J. Foss Recommends "Economics and Identity" by George A. Akerlof and Rachel E. Kranton. In: Frey B, Schaltegger C (eds) 21st century economics. Springer, Cham, pp $49-50$

Giamattei M, Lambsdorff JG (2019) ClassEx-an online tool for labin-the-field experiments. J Behav Exp Finance 22:223-231

Hoffman E, McCabe KA, Smith VL (1998) Behavioral foundations of reciprocity: experimental economics and evolutionary psychology. Econ Inq 36:335-352

Huhtala A (2009) Income effects and the inconvenience of private provision of public goods for bads: the case of recycling in Finland. Ecol Econ 69:1675-1681

Isaac RM, Walker JM (1988) Group size effects in public goods provision: the voluntary contributions mechanism. Q J Econ 103:179-199

Kaoursakis K, Birol E (2008) Investigating household preferences for Kerbside Recycling Services in London: a choice experiment. J Environ Manage 88:1099-1108

Kinnaman TC (2009) The economics of municipal solid waste management. Waste Manag 29:2615-2617

Ledyard JO (1995) Public goods: a survey of experimental research. In: Kagel JH, Roth AE (eds) Handbook of experimental economics. Princeton University Press, Princeton, pp 111-194

List JA, Sadoff S, Wagner M (2011) So you want to run an experiment, now what? Some simple rules of thumb for optimal experimental design. Exp Econ 14:439

Menges R, Schröder C, Traub S (2005) Altruism, warm glow and the willingness-to-donate for green electricity: an artefactual field experiment. Environ Resour Econ 31:431-458

Olson M (1965) The logic of collective action-public goods and the theory of groups. Harvard University Press, Cambridge

Rabin M (1993) Incorporating fairness into game theory and economics. Am Econ Rev 83:1281-1302

Rompf S, Kroneberg C, Schlösser T (2017) Institutional trust and the provision of public goods: when do individual costs matter? The case of recycling. Ration Soc 29:160-178

Schultz WP (1999) Changing behavior with normative feedback interventions: a field experiment on curbside recycling. Basic Appl Soc Psychol 21:25-36

Tietenberg T, Lewis L (2014) Environmental and natural resource economics, 9th edn. Prentice Hall, Harlow

Trudel R (2019) Sustainable consumer behavior. Consum Psychol Rev 2:85-96

Trudel R, Argo JJ, Meng MD (2016) Trash or recycle? How product distortion leads to categorization error during disposal. Environ Behav 48:966-985

Publisher's Note Springer Nature remains neutral with regard to jurisdictional claims in published maps and institutional affiliations. 